\title{
Standardising the assessment of environmental enrichment and tail-docking legal requirements for finishing pigs in Europe
}

\author{
B Hothersall', L Whistance ${ }^{\dagger}, H$ Zedlacher", B Algers ${ }^{\S}, E$ Andersson, M Bracke ${ }^{\#}, V$ Courboulay', \\ P Ferrari", C Leeb ${ }^{\dagger}$, S Mullan*广, J Nowicki", M-C Meunier-Salaün', T Schwarz", L Stadig ${ }^{*}$ and D Main ${ }^{\dagger}$
}

† School of Veterinary Science, University of Bristol, UK

₹ Department of Sustainable Agricultural Systems, University of Natural Resources and Life Sciences (BOKU), Austria

$\S$ Department of Animal Environment and Health, Swedish University of Agricultural Sciences (SLU), Sweden

\# Wageningen Livestock Research, Wageningen University and Research Centre, The Netherlands

^IFIP Institut du Porc, France

* Centro Ricerche Produzioni Animali, Italy

"Department of Swine and Small Ruminants Breeding, University of Agriculture in Krakow, Poland

' Institut National de la Recherche Agronomique (INRA), France

${ }^{2}$ Animal Sciences Unit, Institute for Agricultural and Fisheries Research (ILVO), Belgium

* Contact for correspondence and requests for reprints: Siobhan.Mullan@bristol.ac.uk

\begin{abstract}
An online training package providing a concise synthesis of the scientific data underpinning EU legislation on enrichment and taildocking of pigs was produced in seven languages, with the aim of improving consistency of professional judgements regarding legislation compliance on farms. In total, I58 participants who were official inspectors, certification scheme assessors and advisors from $16 \mathrm{EU}$ countries completed an initial test and an online training package. Control group participants completed a second identical test before, and Training group participants after, viewing the training. In Section I of the test participants rated the importance of modifying environmental enrichment defined in nine scenarios from I (not important) to 10 (very important). Training significantly increased participants' overall perception of the need for change. Participants then rated nine risk factors for tail-biting from I (no risk) to 10 (high risk). After training scores were better correlated with risk rankings already described by scientists. Scenarios relating to tail-docking and management were then described. Training significantly increased the proportion of respondents correctly identifying that a farm without tail lesions should stop tail-docking. Finally, participants rated the importance of modifying enrichment in three further scenarios. Training increased ratings in all three. The pattern of results indicated that participants' roles influenced scores but overall the training improved: i) recognition of enrichments that, by virtue of their type or use by pigs, may be insufficient to achieve legislation compliance; ii) knowledge on risk factors for tail-biting; and iii) recognition of when routine tail-docking was occurring.
\end{abstract}

Keywords: animal welfare, enrichment, inspector, legislation, pig, tail-docking

\section{Introduction}

Animal welfare legislation has been developed for many countries and many species. However, the impact of legislation on animal welfare depends upon its full implementation in practice. In addition to appropriate awareness in the farming community, full implementation of EU legislation requires consistent assessment by those responsible for ensuring compliance. This can include official inspectors responsible for enforcement actions and assessors working for voluntary certification schemes that also aim to ensure compliance with legal prescriptions.

The complexity of the technical interpretation of legislation varies considerably between different requirements, depending on the availability of measurable criteria to define them. For example, assessing compliance with space allowance requirements necessitates measurement of the space, the number and, often, size of the animals housed in that space. In comparison, environmental enrichment is more difficult to quantify and calls for a professional judgement. Standardising this professional judgement is necessary for consistent implementation. This can be particularly challenging when legislation, such as European Directives, is implemented by many different countries each using different inspection regimes.

This study describes an initiative aimed at improving the consistency of professional judgements needed to assess compliance with the environmental enrichment and taildocking requirements for finishing pigs included in EU Directive 2008/120/EC as detailed below: 
...pigs must have permanent access to a sufficient quantity of material to enable proper investigation and manipulation activities, such as straw, hay, wood, sawdust, mushroom compost, peat or a mixture of such, which does not compromise the health of the animals. Annex 1, para 4

Neither tail-docking nor reduction of corner teeth must be carried out routinely but only where there is evidence that injuries to sows' teats or to other pigs' ears or tails have occurred. Before carrying out these procedures, other measures shall be taken to prevent tail-biting and other vices, taking into account environment and stocking densities. For this reason inadequate environmental conditions or management systems must be changed. Annex 1, para 8

These requirements are based upon extensive welfare research on tail-biting in pigs (European Food Safety Authority [EFSA] 2007a, 2014). The legislation is clearly intended to ensure pigs are provided with sufficient resources to satisfy their behavioural needs, to minimise the risks of injurious tailbiting and to avoid unnecessary tail-docking. The interaction between the various management factors is complex. The EFSA (2007a) scientific opinion concluded that:

The occurrence of tail-biting has a multifactorial origin and there is evidence in the report that some causal factors have more weight, such as the absence of straw, the presence of slatted floors and a barren environment" and that "there is little evidence that provision of toys such as chains, chewing sticks and balls can reduce the risk of tail-biting.

The complex nature of the issue has led the UK's Farm Animal Welfare Council (2009) to describe the presence of an intact uninjured tail on a growing pig at slaughter as an "iceberg indicator" because it may "effectively summarise many measures of welfare and is easy to understand." The report even suggested that an intact tail indicates that the "animal's husbandry and management were of high quality and its welfare was good". In addition to the welfare implication, reducing the number and severity of tail lesions can have management benefits: tail-biting and tail lesions have been associated with carcase condemnation (Valros et al 2004; Harley et al 2014).

Assessment of compliance with the enrichment and taildocking regulations requires consideration of both resource and animal-based outcomes. Determining the suitability of "material to enable proper investigation and manipulation activities" requires an assessment of both the substrate (resource) and the pig's behaviour (outcome). Where pigs have been tail-docked an assessment of the "evidence that injuries to..... tails have occurred" (outcome) and of the changes to "inadequate environmental conditions or management systems" (resource) must also be made. The professional judgements associated with the assessment, therefore, necessitate considerable knowledge and understanding of the relevant scientific literature and its practical application.

The Food and Veterinary Office (FVO) is responsible for assessing compliance by each European Union Member State (MS). It observed that the enrichment and taildocking legislation have been inconsistently implemented in many states. Between January 2010 and August 2012, eight FVO mission reports included a specific recommendation concerning inadequate implementation of these requirements (Italy, Slovakia, Hungary, Belgium, Portugal, Austria, Denmark, Czech Republic) and four reported insufficient implementation (Romania, Bulgaria, Italy [in 2010], France). Only two missions reported compliance (Sweden, Lithuania) (Edman 2014). Campaign groups have also pressed for the implementation of environmental enrichment and tail-docking requirements (Eurogroup for Animals 2012; Compassion in Farming [CIWF] 2015). In response to FVO concerns, some Competent Authorities have developed guidance notes and training for Official Veterinarians (OVs) carrying out inspections (eg Ministerie van Landbouw Natuur en Voedselkwaliteit 2012). In some countries industry organisations have also been involved in interpreting the requirement (eg British Pig Executive [BPEX] 2014). More recently, partly influenced by the current study, the European Commission is producing more detailed guidance on the interpretation of the Directive 2008/120/EC.

Previous studies have shown that short educational interventions can improve knowledge of pig management and welfare and positively affect participant attitudes and behaviour (Hemsworth et al 1994; Coleman et al 2000). Wright et al (2009) also found that formative online assessment of case studies improved veterinary students' ability to assess clinical signs of pig health and welfare. The present study describes the development and initial use of an online training package aimed at improving the consistency of the interpretation of the environmental enrichment and taildocking requirements included in EU Directive 2008/120/EC. The project was undertaken as part of a larger initiative, EU WelNet, to improve compliance with various aspects of animal welfare legislation. The remit of the training package was to summarise the welfare science basis for the legislative requirements for finishing pigs concerning environmental enrichment and tail-docking. It included information on the motivation for tail-biting and oral behaviour; risk factors for tail-biting; attributes of effective enrichment material; tail-docking practice and welfare outcomes (oral behaviour and tail lesions).

The evaluation of the training package aimed to explore:

- The extent to which participants took the type of enrichment and pig behaviour (manipulation of enrichment) into account when deciding whether material enables "proper investigation and manipulation activities";

- Whether the online training changed understanding of the following aspects of the Directive: the relative risks of different management practices for tail-biting; legal requirements needed to permit tail-docking; the attributes of adequate enrichment to comply with legislation;

- The effects of participants' professional roles (Official Inspector, Certification Assessor, Farm Advisor or Other) on their responses and whether training resulted in harmonisation of professional judgement (indicated by decreased variability in scores);

- The views of the participants on the usefulness of the training package. 


\section{Materials and methods}

\section{Development of training package}

The materials were produced collaboratively by a group of EU WelNet welfare scientists (the authors and their colleagues), who reviewed existing material including industry guidance, defined a preferred format and agreed the content (available at http://euwelnet.hwnn001.topshare.com). The training comprised a concise synthesis of scientific data underpinning EU legislation on enrichment and tail-docking of finisher pigs. It took approximately $30 \mathrm{~min}$ to read and was designed to be attractive and accessible with illustrations, diagrams and video files to illustrate key-points. The group also consulted with an advisory board, revised the content accordingly and defined an evaluation approach. The advisory board consisted of Chief Veterinary Officers of 27 EU Member States plus Croatia, Norway and Switzerland, EU institutions involved with animal welfare (European Commission Directorate-General for Health and Consumers [DGSANCO], EFSA, FVO); International organisations (World Organisation for Animal Health [OIE], Food and Agriculture Organization of the United Nations [FAO], European Forum for Animal Welfare Councils [EUROFAWC]); European organisations representing animal and meat industries (Copa-Cogeca [represents farmers' lobbies and agricultural co-operatives from the DGSANCO], European Forum of Farm Animal Breeders [EFFAB], International Federation for Animal Health Europe [IFAH], Européenne du Commerce du Bétail et des Métiers de la Viande [UECBV]); Veterinary and welfare science (Federation of Veterinarians of Europe [FVE], International Society for Applied Ethology [ISAE], International Society for Animal Hygiene [ISAH]); Welfare education (European College of Veterinary Public Health [ECVPH], European College of Animal Welfare and Behavioural Medicine [ECAWBM]); Welfare organisations (CIWF, Eurogroup, FourPaws, World Animal Protection) and the European Animal Welfare Platform (FAI). During development, a draft version of the tool was distributed to the board and 15 responses were received from NGOs, competent authorities, science and industry groups from at least eight countries and three EU groups.

Feedback received from the advisory group contained many positive comments. The package was generally considered a useful collation of the science, in an attractive, user-friendly format and suitable for official inspectors. While it explored the relative merits of enrichment materials, the package was not intended to attempt to define their absolute acceptability in terms of compliance with EU legislation. This led to mixed responses from the advisory board. A section on the limitations of different enrichment objects was positively received by some, but others highlighted underlying uncertainties in interpreting the legislation, including the need for clearer official guidance. Some questioned whether the training should also propose practical solutions for fully housed intensive production systems, or they indicated perceived conflicts between science and practice regarding the utility of specific enrichments. Within both the project team and the advisory board, it was considered difficult to find an ideal format for each target audience, and to reconcile different opinions on key technical issues, such as the value of natural foraging behaviour or of enrichment objects and straw. Another challenge was the different versions of the EU Directive amongst member states. For example, the German and Polish translations use the word movement rather than manipulation of materials, which have different connotations. These difficulties were resolved as far as possible by an iterative process of revision and discussion, after which the team translated the final package into English, Dutch, French, German, Italian, Polish and Spanish and recruited participants. The target audience consisted of official veterinarians responsible for assessing compliance with EU legislation within each country (Austria, Belgium, Germany, France, Italy, Spain, Poland, the Netherlands, UK); certification scheme assessors and farm advisors (veterinary surgeons and other advisors). Pig producers did not form part of our final sample, though the tool was also considered suitable for future use with this group. The English language version was also made available to participants in Sweden, who were able to record their responses in Swedish.

\section{Study design}

All participants were invited to complete a demographic questionnaire and were then assigned to the Training or Control group. Assignation was automated and alternated between the two groups, including alternation within 'professional role'. All participants were then asked to complete a 27-question online test (Supplementary file S1 [see supplementary material to papers published in Animal Welfare on the UFAW website: http://www.ufaw.org.uk/t-ufaw-journal/supplementarymateriai]) and described in Analysis) twice. Seven days after completing the first iteration of the test, participants were invited to log in again. Control group participants were then presented with the second iteration of the test (identical to the first) followed immediately by access to the training package, whereas Training group participants were directed to the training package and immediately after reaching the final page, to the test.

\section{Feedback questionnaire}

Following the second iteration of the test, participants were asked to complete a feedback questionnaire consisting of nine statements concerning the effect of the training on their confidence and understanding of EU legislation relating to tail-docking and enrichment. Participants could rate their agreement with each statement on a 10-point scale with anchors at 1 (no agreement) and 10 (full agreement). 


\section{Analysis}

\section{Quantitative analysis}

Except where otherwise specified, random-intercept nested models were generated in MLwiN v2.25 for each question. The random effects were specified as Test iteration (1 or 2) as Level 1, nested within Participant (Level 2) within Country (Level 3). This multi-level structure allowed us to adjust for non-independence due to clustering within groups - for example, the tendency of an individual participant to give high scores, or of those from a particular country to score low. The influence of the following variables (fixed effects) on participants' scores were evaluated: test iteration ( 1 or 2 ), the professional role of the participant (Official Inspector, Certification Assessor, Farm Advisor or Other) and the interaction between group (training or control) and iteration. Inclusion of Iteration (1 or 2) as both a fixed and a random effect meant that it was treated as a repeated measure; the 'training $\times$ group' interaction was used to identify a divergence in scores between the groups following training, which would indicate a significant effect of training. The significance of individual predictors in a model was tested using $Z$-tests, whereby the coefficient was divided by the standard error of coefficient to generate respective $Z$-values. $P$-values were calculated as the area of the normal distribution greater than or equal to the $Z$-value, multiplied by two (two-tailed analysis). The significance of interactions in a model was tested using $\chi^{2}$ tests and the deviance in log-likelihood between models both with and without the interaction. Data were transformed as necessary and standardised residuals were calculated and plotted to ensure that assumptions of normality and homoscedasticity were met.

In Section 1 of the test, participants were presented with nine scenarios (see File S1; http://www.ufaw.org.uk/theufaw-journal/supplementary-material) and, for each, they were asked to rate the importance of modifying the enrichment in order to comply with EU legislation, from 1 (not important) to 10 (very important). Analysis examined the influence of various factors on the score given. Eight of the nine questions (scenarios) in this section were identical to another question except for the type of enrichment object present (clean, dry straw; wet, dirty straw; wood; or a chain), or the presence or absence of manipulation of the object (ie the scenario specified whether or not pigs were manipulating the object[s]). For this section, a slightly different structure was applied: a single model was generated using data from the eight 'paired' questions and Question (Level 1) was nested within Participant (Level 2) nested within Country (Level 3). Enrichment object type and presence/absence of manipulation were added as fixed effects in addition to the fixed effects listed above.

Section 2 focused on knowledge of tail-biting risk factors. Nine risk factors were listed (File S1; http://www.ufaw.org.uk/the-ufaw-journal/supplementarymaterial) and participants rated the level of risk from 1 (no risk) to 10 (high risk). We examined non-parametric correlations (Kendall's Tau) between the ranking of risk calculated by EFSA (2007a) and the ranking given by participants at each of the two time-points. Tied ranks were assigned if values given by EFSA (2007a) were equal. One risk factor in our test ('pigs of different breeds within a group') was not mentioned in the EFSA chart; it was included for comparison purposes and assigned the rank of zero (no risk). We then further examined the changes observed by creating nested models for each individual question.

Section 3 tested participants' knowledge of the legal requirements needed to permit tail-docking. It described four scenarios relating to tail-docking and management (File S1; http://www.ufaw.org.uk/the-ufaw-journal/supplementarymaterial) and participants selected the action required from four options: none; identify and make suitable management changes; stop tail-docking; or permit tail-docking. Participants could choose more than one answer. Responses were initially recoded as a binary variable: correct (only the correct answer selected) or incorrect (one or more wrong answers selected, including where the participant also selected the correct answer) for each question. McNemar's tests were conducted separately for the Control and Training groups to examine the change in the proportion of correct answers between the two iterations.

In Section 4, participants were presented with three further scenarios (File S1), this time focusing on the relationship between tail-biting behaviour and the attributes of the enrichment provided. They were again asked to rate the importance of modifying enrichment in each case in order to comply with EU legislation. This was again analysed by nested models of each question but respondents were also asked to give their own opinion on appropriate action (see Qualitative analysis).

Finally, to examine whether training resulted in harmonisation of participants' views, we calculated values for Levene's test of equality of variance for each of the variables where the group $\times$ training interaction proved significant. The test was calculated once at each iteration and compared Control and Training group participants' scores.

After completing the second iteration of the test, participants were invited to provide feedback on the usefulness of the training package by indicating their agreement $(0=$ no agreement; $10=$ full agreement) with nine statements.

\section{Qualitative analysis}

Within Sections 4 and 5 free-text questions provided participants with an opportunity to express their own understanding of the legislation (File S1; http://www.ufaw.org.uk/the-ufawjournal/supplementary-material). After rating the importance of modifying enrichment in each scenario in Section 4, participants were asked what they would do next on this farm in their current role. It was then pointed out that different countries and organisations interpret the EU Directive differently; participants were further asked what they would do if they were free from any such interpretations, and why. Section 5 presented two further scenarios and free-text questions. The first asked what the participant would do next in this situation. They were then given additional details about environmental, management or behavioural factors and asked what they would now do next. 


\section{Results}

In total, 158 participants (76 Control and 82 Training) from 16 countries completed both iterations of the test, including 83 official inspectors, 23 certification scheme assessors and 24 farm advisors. The remaining 28 respondents were classified as 'Others'.

\section{Quantitative analysis}

All results report predicted means ( \pm SEM) unless otherwise stated.

\section{Section I - Importance of modifying enrichment ('paired' pooled data from 8 scenarios)}

The type of enrichment object had significant effects on participants' scores, as did presence/absence of evidence that pigs were manipulating the object(s). For object type $(P<0.001)$ all four types differed from each other. Participants gave the lowest scores (least important to modify the enrichment) for clean, dry straw followed by wood, followed by a chain, and the highest scores (greatest need for change) where the question specified that wet and dirty straw was present. Manipulation of those materials by pigs decreased scores by $0.80( \pm 0.12)(P<0.001)$. Scores were also influenced by participants' professional role $(P<0.001)$, with Official Inspectors and Others scoring significantly higher than Farm Advisors. Certification advisors' scores were intermediate and did not differ significantly from any of the other categories.

The interaction between Group and Iteration was also significant $(P<0.001)$. This reflected very similar scores for the Control and Training groups at Iteration 1, with scores increasing (greater need for change) in the Training group only at Iteration 2 (Figure 1).

\section{Section 2 - Risk factors for tail-biting}

At Iteration 1, participants' ranking of risk factors for tailbiting were already significantly correlated with the ranks shown in the EFSA (2007a) table (Training group and Control group, both Kendall's Tau $=0.572 ; P=0.035)$. At Iteration 2 the correlation explained more of the variability and was more significant in both groups, but the change was greater in the Training group (Control group, Tau $=0.629 ; P=0.02$; Training group, Tau $=0.800 ; P=0.003)$. Modelling of the data for individual questions revealed that this was due to a significant Group $\times$ Iteration interaction for three of the variables. Participants rated the risk posed by a 'barren environment' as very high in the initial test but this, nonetheless, increased significantly after training (Iteration 1: Training group 8.96; Control group 9.28. Iteration 2: Training group 9.54; Control group 9.08; $P=0.002$ ). Conversely, training led to moderate decreases in risk ratings for 'heat stress' (from 7.90 to 6.84 in the Training group, whereas Control group scores went from 8.04 to $8.22 ; P=0.0003$ ) and 'high stocking density' (from 8.95 to 8.18 in the Training group; from 9.07 to 8.91 in the Control group; $P=0.005$ ). The latter decreases were in accordance with the information provided during training. Professional role did not significantly affect scores for any of these three variables. The variable 'pigs of different breeds within a group' (which is not a recognised risk) was not mentioned in the training and training did not significantly affect scores for this variable either.

\section{Figure I}

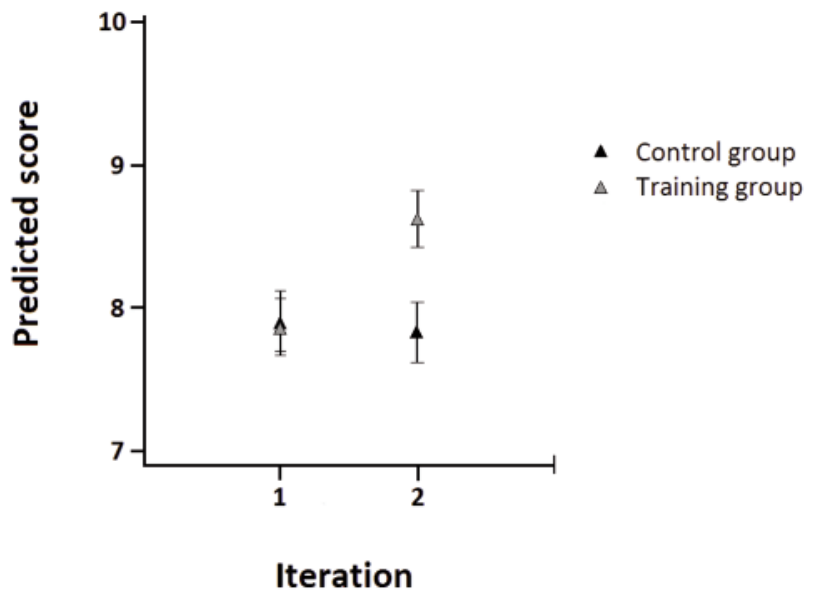

Mean ( \pm SEM) group scores for pooled questions in Section I. Participants were given descriptions of enrichment and its use by pigs, and asked to score, on a scale from 0 to 10, the importance of modifying the enrichment provided, in order to comply with legislation. Scores are shown for Iteration I (before training) and Iteration 2 (after training). A higher score indicates a greater need for change.

Section 3 - Tail-biting and management practices — identification of action required to achieve compliance (four scenarios)

There was no significant change between Iterations 1 and 2 in the proportion of Control group participants identifying the correct action in any of the four scenarios about tail-biting and management practices. In contrast, Training group responses changed significantly in two of the scenarios. In Question 19, following training there was a significant decrease (McNemar's test; $P=0.035$ ), from 33 to $18 \%$ in the percentage of participants correctly recognising that no action was required at a farm which had made suitable management changes after a recent tail-biting outbreak (Figure 2[a]; control group responses are shown for comparison in Figure 2[b]). The scenario stated that there were no pigs with fresh tail lesions but that pigs with healed tail lesions were present. Following training, 56\% of Training group participants incorrectly answered that the farm should stop taildocking, compared with 34\% in Iteration 1. In Question 20 , the proportion of respondents correctly identifying that a farm with no evidence of tail lesions should stop tail-docking increased significantly from 60 to $80 \%$ after training (McNemar's test; $P=0.001$ ) (Figure 2[c]; control group responses Figure 2[d]). No significant improvement was seen in either of the remaining questions, where correct scores were already very high at Iteration 1: over $80 \%$ in Question 21 and over 90\% in Question 22 (see supplementary files S1 [questionnaire] and S2 (results summary [supplementary material to papers published in Animal Welfare on the UFAW website: http://www.ufaw.org.uk/the-ufaw-journal/ supplementary-materiai]). 
Figure 2

(a)

(b)
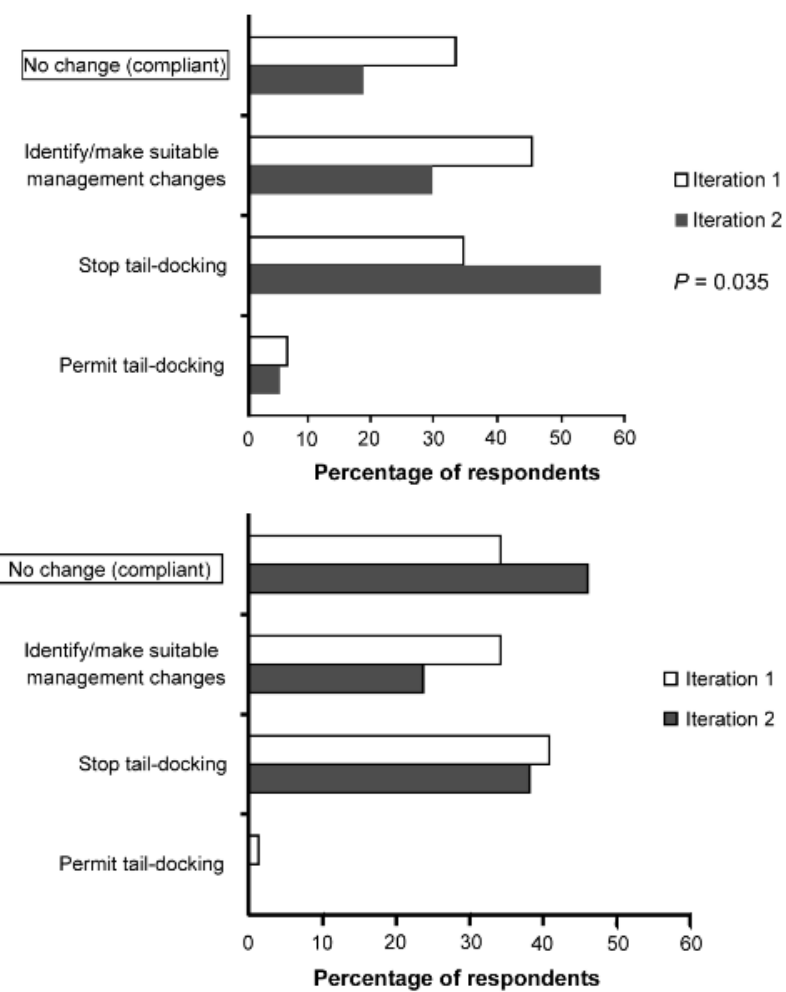

(c)

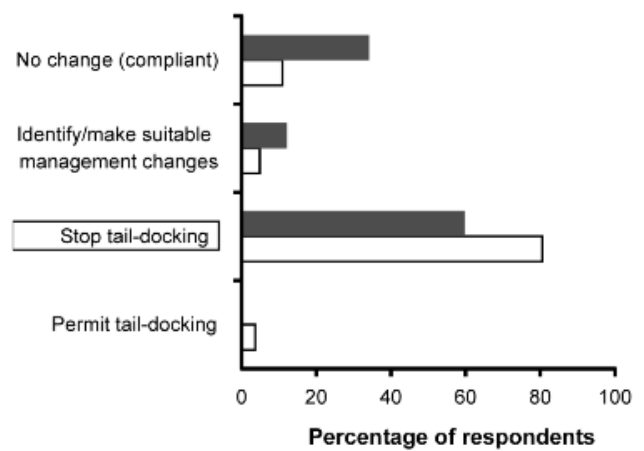

(d)

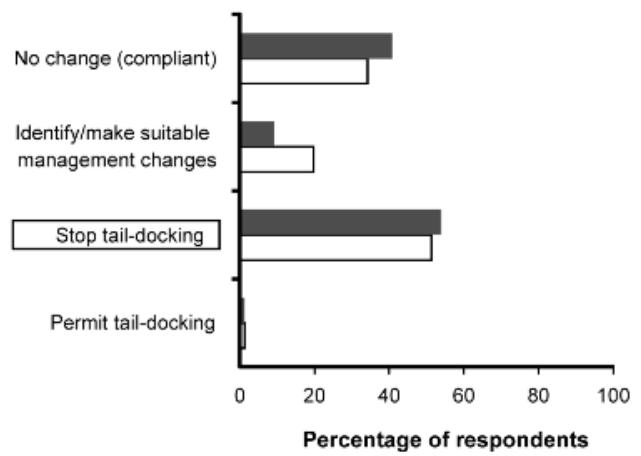

Distribution of answers in Section 3. Scenarios relating to tail-biting and management practices were described. Respondents were asked to identify the action required to achieve compliance. They could select more than one answer. The correct answer is marked by a black outline. Question 19: All pigs are tail-docked. A recent outbreak of tail-biting has occurred; suitable management changes have been made in response. Pigs with healed tail lesions are present. No pigs with fresh tail lesions are present with (a) training group and (b) control group. Question 20: All pigs are tail-docked. Current management practices are suitable. No pigs with healed lesions and no pigs with fresh tail lesions are present with (c) training group and (d) control group.
Section 4 - Importance of modifying enrichment (three scenarios)

In all three of the scenarios in Section 4 there were significant Training Group $\times$ Iteration interactions, indicating that training increased scores by between 0.29 and 1.3 ; there were also significant effects of the professional role of the participant (Table 1).

The first scenario (Question 23) described a barren environment. Official Inspectors scored higher (greater need to modify enrichment) than Farm Advisors; other pairs of roles did not differ significantly in their scores. At Iteration 2, scores increased slightly in the training group and decreased slightly in the control group. In the second scenario (Question 24), tail lesions were present and pigs were provided with but not manipulating straw that was wet and dirty. Official Inspectors again scored highest, giving significantly higher ratings than either Farm Advisors or Other. The significant Training Group $\times$ Iteration interaction represented an increase in scores at Iteration 2 in the training group only.

For both of these questions, the majority of respondents gave the maximum score of 10 . This resulted in means for all Group/Iteration combinations of $\geq 9.52$ and 8.29 for Questions 23 and 24, respectively. As a result, the data could not be satisfactorily transformed and model estimates may be imprecise, so should be interpreted with caution.

In the final scenario (Question 25), pigs were able to reach two chains but were only manipulating one; there were no pigs with tail lesions. All groups scored a lesser need for change (lower score) in this scenario and, in contrast with the previous scenarios, scores of Official Inspectors (5.20 $\left.\left[\begin{array}{ll} \pm & 0.58\end{array}\right]\right)$ and Farm Advisors (4.12 $[ \pm 0.72])$ overlapped and were both significantly lower than those of Certification Assessors $(6.63[ \pm 0.73])$ or Others $(6.53[ \pm 0.72])$, which did not differ from one another. Again, the significant Training Group $\times$ Iteration interaction represented an increase in scores at Iteration 2 in the training group only.

\section{Equality of variance as a measure of harmonisation}

For each of the questions where the group $\times$ training interaction proved significant, Levene's test of equality of variance was calculated. This compared Control and Training group participants' scores and was calculated once at each iteration.

At Iteration 1, variance was significantly different for only one of eleven questions: Section 4, Scenario 1 (importance of modifying enrichment: barren environment; tail lesions present, $f=4.65 ; P=0.033$ ), where variance was greater within the Training group than within the Control group.

At Iteration 2, variance differed significantly between Training and Control groups for ten of the eleven questions. In eight of these ten cases, variance was now lower in the Training group than the Control group, indicating that training had reduced variability in the scores given (ie harmonised judgement). The two cases in which variance was higher in the Training group were Q2 (heat stress) and Q9 (high stocking density) in the 'risk factors' (Section 2). The multi-level analysis had previously revealed that training group scores for these two risk factors decreased after training, consistent with the information provided in training. 
Table I Model predictions for the effects of Training Group $\times$ Iteration interaction and professional role in Section 4. Participants were presented with farm scenarios and asked to score the importance of modifying the enrichment provided, in order to comply with legislation. A higher score indicates a greater need for change. Co-efficients represent the predicted change in score relative to the reference categories specified in the model (here: Iteration $=\mathrm{I}$, Training group = Control, Role = Official Inspector). Roles differing from Official Inspector are shown in bold; a negative co-efficient indicates scores were lower, and a positive one higher.

\begin{tabular}{|c|c|c|c|c|}
\hline \multirow[t]{2}{*}{ Question } & \multicolumn{4}{|c|}{ Training $\times$ Iteration interaction Professional role* } \\
\hline & Co-efficient (SE) & $P$-value & Co-efficient (SE) & P-value \\
\hline Q23: Barren environment; no substrate or enrichment; tail lesions present & $+0.29(0.10)$ & 0.006 & $\begin{array}{l}\text { CA: }-0.27(0.15) \\
\text { Other: }-0.23(0.14) \\
\text { FA: }-\mathbf{0 . 4 0}(\mathbf{0 . 1 4})\end{array}$ & 0.02 \\
\hline Q24: Wet, dirty straw; no manipulation of straw; tail lesions present & $+0.57(0.22)$ & 0.01 & $\begin{array}{l}\text { CA: } 0.28(0.32) \\
\text { Other: }-0.65(0.30) \\
\text { FA: }-0.74(0.31)\end{array}$ & 0.05 \\
\hline Q25: Two chains in reach; one manipulated; no tail lesions present & $+|.3|(0.44)$ & 0.003 & $\begin{array}{l}\text { CA: I.43 (0.59) } \\
\text { Other: I.33 (0.55) } \\
\text { FA: }-1.09(0.57)\end{array}$ & 0.006 \\
\hline
\end{tabular}

* CA = Certification Assessor; FA = Farm Advisor.

\section{Qualitative analysis}

In Section 4 (three scenarios exploring the importance of modifying enrichment) and Section 5 (additional two detailed scenarios followed by further information) participants were asked 'what would you do?' The aim of the questions was to encourage participants to describe their own professional response to the scenarios. Unfortunately, most respondents reported the actions that should be taken by the farmer (eg 'check ventilation' or 'provide more enrichment') making it difficult to analyse the impact of the training tool on the participants. Even though respondents were not specifically asked to provide their opinion on the enforcement of legislation, some comments were included in the question about their role. There was a full range of suggestions, such as arguing for allowing or banning routine tail-docking, permitting more flexible interpretation to suit the local conditions or suggesting greater harmonisation of enforcement.

\section{Feedback questionnaire}

In total, 150 of the participants completed the feedback questionnaire for the training tool (Table 2). Responses indicated that it was very well received, with mean scores of at least 7.49/10 for all questions. The highest mean score (8.81) was given in response to the statement asking whether participants would recommend the tool to others involved in assessing finisher pig welfare. The lowest mean score (7.49) was given for the better understanding of production losses associated with tail-biting.

\section{Discussion}

The development of the training package demonstrated that a large group of welfare scientists were able to work collaboratively and incorporate diverse viewpoints to create a product that was received well by both the advisory board (as described in Development of tool) and the intended audience (according to their feedback). The evaluation provided encouraging confirmation that participants had a good general understanding of the legislation and took the attributes and use (manipulation) of enrichment into account when assessing compliance. Moreover, the training package had a significant positive influence on participants' understanding of the relevant legislative requirements, the importance of modifying certain enrichments and of certain tail-biting risk factors. While training did not influence every individual question, results consistently indicated that it improved participants' understanding of situations where compliance was relatively difficult to assess. Professional judgements were also consistently harmonised when assessed immediately after training, measured by a reduction in variability of scores. No such pattern of changes was seen for Control group participants. Responses to the feedback questionnaire were very positive, with respondents particularly reporting that they would recommend the training package to colleagues. Indeed, following initial dissemination of the results, the project team has received interest and requests to use the training package from a number of sources.

In Section 1, participants took enrichment properties and use into account when assessing their suitability: they gave lower scores (less need to modify enrichment) when the objects or substrate were manipulated, and when clean, dry straw was given compared with other enrichments. This was in line with the scientific evidence (Moinard et al 2003; van de Weerd et al 2006; EFSA 2007b; Scott et al 2007a,b; Studnitz et al 2007) summarised in the training package. Training group overall scores (for the eight 'paired' questions) increased at Iteration 2, demonstrating that training was effective in increasing awareness of enrichments that would be less likely to comply with legislation. This suggests that a training package might help minimise variation in professional judgements of legislation compliance. However, it is also probably reasonable to suggest that further official guidance on the principles of suitable enrichment and acceptability of specific common enrichments 
Table 2 Summary of feedback on training tool from 150 participants. Score: I = no agreement to I $0=$ full agreement. Statements are ordered by decreasing mean.

\begin{tabular}{|c|c|c|}
\hline $\begin{array}{l}\text { Question } \\
\text { number }\end{array}$ & $\begin{array}{l}\text { Please indicate your level of } \\
\text { agreement with the following } \\
\text { statements }\end{array}$ & Mean ( \pm SD) \\
\hline 9 & $\begin{array}{l}\text { I would recommend this training tool } \\
\text { to other persons involved in assessing } \\
\text { the welfare of finisher pigs in the EU }\end{array}$ & $8.81( \pm 1.89)$ \\
\hline 3 & $\begin{array}{l}\text { The training has increased my } \\
\text { understanding of which enrichment } \\
\text { materials best enable the expression } \\
\text { of 'proper investigation and } \\
\text { manipulation activities' }\end{array}$ & $8.16( \pm 2.25)$ \\
\hline 6 & $\begin{array}{l}\text { The training has increased my } \\
\text { understanding of the EU legislation } \\
\text { related to enrichment provision }\end{array}$ & $7.85( \pm 2.33)$ \\
\hline 4 & $\begin{array}{l}\text { The training has increased my } \\
\text { understanding of the relationship } \\
\text { between tail-biting and housing and } \\
\text { management practices }\end{array}$ & $7.83( \pm 2.14)$ \\
\hline 2 & $\begin{array}{l}\text { The training has increased my } \\
\text { understanding of the relationship } \\
\text { between tail-biting and a lack of } \\
\text { opportunity to express foraging } \\
\text { behaviour and other investigation } \\
\text { and manipulation activities }\end{array}$ & $7.83( \pm 2.29)$ \\
\hline I & $\begin{array}{l}\text { The training has increased my } \\
\text { understanding of the importance for } \\
\text { pigs to be able to express foraging } \\
\text { behaviour and other investigation } \\
\text { and manipulation activities }\end{array}$ & $7.82( \pm 2.39)$ \\
\hline 8 & $\begin{array}{l}\text { The training has increased my confidence } \\
\text { in interpreting EU legislation on farms. }\end{array}$ & $7.71( \pm 2.43)$ \\
\hline 7 & $\begin{array}{l}\text { The training has increased my } \\
\text { understanding of the EU legislation } \\
\text { related to tail-docking of pigs }\end{array}$ & $7.48( \pm 2.67)$ \\
\hline 5 & $\begin{array}{l}\text { The training has increased my } \\
\text { understanding of the relationship } \\
\text { between tail-biting and production } \\
\text { losses }\end{array}$ & $7.46( \pm 2.47)$ \\
\hline
\end{tabular}

might have an even greater influence on reducing the variability in the assessment of compliance.

Encouragingly, participants' rankings of risk factors in Section 2 already correlated with those published by EFSA (2007a) prior to training. The strength and significance of the correlation increased for both groups, suggesting that taking part in the test prompted reflection. Nevertheless, the increase was greater for the Training group and analysis of individual risk factors indicated that the changes were in accordance with the information provided in training.

When participants were given scenarios and asked to identify the action needed to ensure compliance (Section 3), significant changes were seen across the iterations for the training group only. Knowledge was improved after training in one question, but the percentage replying correctly actually decreased in another. The latter concerned a situation where tail-biting appeared to have stopped. The test describes two very similar but not identical situations. It was intended to force participants to find those small differences in scenarios that could be reflected in practice, but it failed. The problem could be of several origins including construction of the training tool, general principles and imperfections in e-learning systems, and last but not least the individual perception of participants. Throughout the training tool, a large amount of information was given about the legislative, biological and environmental background of tail-biting and tail-docking. Some situations describing compliance or the lack of compliance with the legislation were not stated until the last section of the training tool, leading perhaps to decreased attention of participants and thus an incorrect interpretation of some scenarios described in the test. Training may therefore have engendered greater confidence that management changes would resolve the problem, allowing the producer to cease tail-docking straight away. This problem could also indicate a wider imperfection of e-learning formats. Data from literature on distance learning show that some technical aspects of an etool lead to uniformity, which can be an obstacle in interpretations of dynamic situations, especially in heterogeneous environments (Birnbaum 2001). More broadly, Greatrix (2001) argues that standardising assessment cannot itself guarantee that assessors are comparable and that those being assessed meet or even understand the standards required of them. Some of the answers during the second iteration suggested that some participants applied the legislation simply and in a uniform way for decision-making, without analysing individual farm situations. The increase in wrong answers to question 19 was very similar to the increase in correct answers to question 20, suggesting that some participants in both scenarios made a decision using a uniform scheme. No change was seen for the other two scenarios, where compliance or non-compliance was arguably more obvious. Most respondents answered these correctly at Iteration 1, leaving little room for improvement. The pattern of improvement was again seen in Section 4, where scores in all three scenarios increased at the second iteration in the Training group but not in the Control group. This was despite already very high initial scores for both groups in the first (barren environment) and second (wet, dirty straw) scenarios. The third scenario described the provision of chains that were partly being manipulated and was probably the least obvious to assess as compliant or non-compliant.

Equality of variance tests provided evidence that training also harmonised professional judgements. Training and Control group participants were very similar in the variability of their answers at the first iteration. Of all the questions that were influenced by training, variance differed in only one out of eleven questions: Training participants were more variable. In contrast, at Iteration 2, variance differed in ten of the eleven cases. In eight cases, Training participants were now less variable than Controls, suggesting that — as intended — the effect of training was to make their assessments more similar. Interestingly, the opposite result was seen for the remaining two questions: for 'heat stress' and 'high stocking density' in the Section 2 
risk factors, the groups did not differ significantly at Iteration 1 but the Training group was more variable after training. Modelling of responses to these individual questions indicated that mean ranks assigned to them decreased after reading the training package, which presented participants with evidence that these were relatively low risk factors. The increase in variance suggests that not all participants picked up on this, so future training could elaborate on or emphasise such information further. This may also reflect the training package's focus on environmental enrichment and future training tools could target additional risk factors if desired.

Anneberg et al (2012) reported that Danish livestock producers perceived welfare inspectors as 'outsiders' who, as such, are unable to make fair judgements of farms. The authors raised the question of whether the authoritative position of inspectors discourages dialogue or farmers' motivation to make improvements. Our survey included providers of advice and guidance as well as those with a statutory remit, and our modelling structure allowed us to investigate the effect of professional role on participants' responses. Role influenced scores in Sections 1 and 4, though not in Section 2 (explored for individual risk factors whose scores were influenced by training). In Section 1 and in two of the three scenarios of Section 4, Official Inspectors gave higher scores (greater need to improve enrichment) compared with Farm Advisors. However, in the third scenario (chains provided with 1 of 2 being manipulated; no lesions), Official Inspectors gave scores as low, or lower, than the other groups. It is plausible that Official Inspectors' role gave them greater authority or confidence to require changes of producers, but the latter result suggests that they (more than other groups) interpreted chains as compliant. If Official Inspectors commonly observe chains in use as enrichment, it may be that they judge them as compliant if they appear to be effective in preventing tail-biting. Farm Advisors are likely to have similar experiences and their scores for this scenario were also low; it is possible that Certification Assessors had reference to additional scheme-specific criteria which encouraged them to view chains as non-compliant.

Unfortunately, the methodology used in this paper did not produce a reliable description of the participant's professional response whilst attending pig farms. It is suggested that in-depth interviews and observing farm visits as used by Roe et al (2011) would be required to understand the complex interaction between the legislative requirements, the farmer and the role of assessor or advisor.

Since this EU legislation is controversial it is not surprising that respondents used the free text option to comment on enforcement of legislation. Options to improve enforcement have been discussed by Lerner and Algers (2013) and reiterated in a recent report to the European Parliament Committee on Petitions examining implementation of Directive 2008/120/EC (Marzocchi 2014). A survey of European pig farmers reported a consensus that legislation and regulation needed to be harmonised across nations to ensure a 'level playing field', tempered by concerns from some that selected welfare measures 'may conflict with farmers' definitions of animal welfare and good farming practices' (Bock \& van Huik 2007). In Anneberg et al's 2012 study, farmers stated a desire for a set of rules and mentioned the importance of these in ensuring quality assurance. Yet the same individuals believed that assessment of compliance should reflect the producer's individual situation, citing aspects such as facilities, staffing, experience and the overall quality or productivity of the farm. They also argued that inspections are subjective or inconsistent depending on an inspector's personality, attitude or personal interpretation of the legislation (Anneberg et al 2012). If true, this is worrying, but empirical data are scarce. Mullan et al (2011) found that attitude to farm animal welfare did not confound training in pig welfare outcome measures in a group of UK farm assurance assessors, but as borne out by our results, many factors may still influence the response of an assessor once a problem is identified.

The changes brought about by training were modest, resulting in group differences of no more than 2 in mean scores at Iteration 2. Training was intentionally brief, and a more in-depth intervention might be needed to influence scores more strongly. Our focus was on presenting a digest of scientific evidence, but the materials could easily be adapted to include additional clarification of legislative requirements and even official guidance as part of a wider initiative aimed at promoting compliance with the EU Directive. For a number of questions, the capacity for training to increase scores was limited because initial scores or correct responses were already high, indicating that participants already perceived a great need for change or had already identified the appropriate action. Inclusion of scenarios of varying 'difficulty' was helpful to identify where participants needed additional guidance or clarification of the legislation, but the ceiling effect may have been exacerbated by the use of Likert items and a numeric response format, where it was possible to give many items high or low ratings. The use of this format was considered carefully during development; it was considered to reduce ambiguity or bias due to difficulties in translating option answers or descriptors (eg Harris-Kojetin et al 1999). Use of agreement scales also maintained the focus on users' perceptions of the legislation rather than attempting to provide definitive interpretation of compliance or noncompliance in more debatable cases. Overall, the pattern of results showed training helped participants to identify (or increased their perception of the need to modify) enrichments that were less likely to achieve compliance. It was not possible to monitor contact between participants following training or testing and we acknowledge that discussion of the contents of the training package (or even simply dialogue about the legislation) could have affected participants' score. It would be very difficult to avoid this problem in any online, multi-country evaluation, but it is a potential confound that cannot be quantified. Indeed, simply taking part in the study may have increased awareness of the relevant legislation in both Control and Training group participants. 
For logistical reasons, the evaluation was restricted to a short-term assessment immediately after training. Foshay and Tinkey (2007) note that recall of knowledge attained through training is likely to diminish over time, and that written tests examine declarative knowledge without necessarily reflecting professional competence. In previous evaluations of a short educational intervention ( $1 \mathrm{~h}$ information session plus written/visual handouts; (Hemsworth et al 1994) and a supplementary small group session (Coleman et al 2000) improvements in knowledge about pig husbandry and welfare had positive effects on the attitude and behaviour of farm staff. It was beyond the scope of the current study to assess whether training influenced the decisions or actions taken by assessors when subsequently assessing farms. It was also recognised during the development of the project that the training package would have limited impact directly on farmers, although it was considered suitable for them. Farmer-focused initiatives will also be needed to promote compliance with legislation.

\section{Animal welfare implications}

Animal welfare legislation is designed to afford some protection to animals and ensuring appropriate enforcement is part of the way that this is achieved. Improving the understanding of welfare legislation of official inspectors, inspectors of voluntary certification schemes and farm advisors is the first step towards the goal of farmers making changes to achieve legislation compliance and improve welfare. The training package proved a valuable tool in this first step, however, further research is required to evaluate how inspectors' improved understanding of the legislation affects their actions on farms and on subsequent changes undertaken by farmers.

\section{Conclusion}

The training package presented an attractive, accessible summary of the scientific basis for the legislation on environmental enrichment and tail-docking contained within EU Directive 2008/120/EC. The package was designed for professionals involved in the assessment of finisher pig welfare and was well received by participants. Shortterm evaluation indicated that completing the training improved the consistency of participants' professional judgements and improved knowledge of several aspects of the legislation, particularly where assessment of compliance might be considered contentious or difficult. Participants strongly agreed that they would recommend the training package to other persons involved in assessing the welfare of finisher pigs in the EU.

\section{References}

Anneberg I, Vaarst M and Sørensen JT 20I2 The experience of animal welfare inspections as perceived by Danish livestock farmers: A qualitative research approach. Livestock Science 147: 49-58. http://dx.doi.org/10.1016/j.livsci.2012.03.018

Birnbaum R 2001 Management Fads in Higher Education. Where They Come From, What They Do, Why They Fail. Jossey-Bass: San Francisco, USA Bock BB and van Huik MM 2007 Pig farmers and animal welfare: a study of beliefs, attitudes and behaviour of pig producers across Europe. In: Kjaernes U, Miele M and Roex J (eds) Attitudes of Consumers, Retailers and Producers to Farm Animal Welfare, Welfare Quality Report no 2 pp 73-124. Welfare Quality: Lelystad, The Netherlands

BPEX 2014 Environmental Enrichment, Examples. British Pig Executive: UK. http://www.bpex.org.uk/health-welfare/welfare/environment-enrichment/environmental-enrichment-examples/

CIWF 2015 Project Pig. Compassion in World Farming, UK. http://www.ciwf.org.uk/our-campaigns/pigs/

Coleman GJ, Hemsworth PH, Hay M and Cox M 2000 Modifying stockperson attitudes and behaviour towards pigs at a large commercial farm. Applied Animal Behaviour Science 66: I I-20. http://dx.doi.org/I0.1016/S0168-I59I(99)00073-8

Edman F 2014 Do the Member States of the European Union comply with the legal requirements for pigs regarding manipulable material and tail docking? Swedish University of Agricultural Sciences, Uppsala, Sweden EFSA 2007a The risks associated with tail biting in pigs and possible means to reduce the need for tail docking considering the different housing and husbandry systems. The EFSA Journal 61 I: 1-13

EFSA 2007b Animal health and welfare in fattening pigs in relation to housing and husbandry. The EFSA Journal 564: I-I4

EFSA 2014 Scientific Opinion concerning a multifactorial approach on the use of animal and non-animal-based measures to assess the welfare of pigs. EFSA Journal 12(5): 3702. http://dx.doi.org//0.2903/j.efsa.2014.3702

Eurogroup for Animals 2012 Danish member makes formal complaint to European Commission about tail docking. Eurogroup for Animals: Brussels, Belgium

FAWC 2009 Farm Animal Welfare: Past, Present and Future. Farm Animal Welfare Committee: London, UK

Foshay WR and Tinkey PT 2007 Evaluating the effectiveness of training strategies: Performance goals and testing. Ilar Journal 48: I56-I62. http://dx.doi.org//0.1093/ilar.48.2.156

Greatrix P 2001 Quality assurance into the 21 st century: Command and control or enlightened accountability? Perspectives 5: 12-16. http://dx.doi.org//0.1080//3603/00150505208

Harley S, Boyle LA, O'Connell NE, More S], Teixeira DL and Hanlon A 2014 Docking the value of pigmeat? Prevalence and financial implications of welfare lesions in Irish slaughter pigs. Animal Welfare 23: 275-285. http://dx.doi.org//0.7/20 109627286.23.3.275 
Harris-Kojetin LD, Fowler FJ, Brown JA, Schnaier JA and Sweeny SF 1999 The use of cognitive testing to develop and evaluate CAHPS (TM) 1.0 core survey items. Medical Care 37: MSI0-MS2I. http://dx.doi.org//0.1097/00005650-I9990300I00002

Hemsworth PH, Coleman GJ and Barnett JL 1994 Improving the attitude and behaviour of stockpersons towards pigs and the consequences on the behaviour and reproductive performance of commercial pigs. Applied Animal Behaviour Science 39: 349-362. http://dx.doi.org/10.1016/0168-I59I(94)90168-6

Lerner $\mathbf{H}$ and Algers B 2013 Tail docking in the EU: a case of routine violation of an EU Directive. In: Röcklinsberg $\mathrm{H}$ and Sandin P (eds) The Ethics of Consumption: The Citizen, The Market, and The Law pp 374-378. Wageningen Academic Publishers: The Netherlands. http://dx.doi.org//0.3920/978-90-8686-784-4_60

Marzocchi 02014 Routine tail-docking of pigs. European Parliament Directorate General for Internal Policies: Brussels, Belgium

Ministerie van Landbouw Natuur en Voedselkwaliteit 2012 Goede afl eiding voor uw varkens. Ministerie van Landbouw Natuur en Voedselkwaliteit: The Netherlands. [Title translation: Good enrichment for pigs]

Moinard C, MendI M, Nicol CJ and Green LE 2003 A case control study of on-farm risk factors for tail biting in pigs. Applied Animal Behaviour Science 81: 333-355. http://dx.doi.org/10.1016 ISO I68-I59I (02)00276-9

Mullan S, Edwards SA, Butterworth A, Whay HR and Main DCJ 201 I A pilot investigation of Farm Assurance assessors' attitude to farm animal welfare as a confounding factor to training in pig welfare outcome measures. Animal Welfare 20: 4|3-42I
Roe E, Buller $\mathbf{H}$ and Bull J 20I I The performance of farm animal assessment. Animal Welfare 20: 69-78

Scott K, Chennells DJ, Armstrong D, Taylor L, Gill BP and Edwards SA 2007a The welfare of finishing pigs under different housing and feeding systems: liquid versus dry feeding in fully-slatted and straw-based housing. Animal Welfare 16: 53-62

Scott K, Taylor L, Gill BP and Edwards SA 2007b Influence of different types of environmental enrichment on the behaviour of finishing pigs in two different housing systems 2. Ratio of pigs to enrichment. Applied Animal Behaviour Science 105: 5I-58. http://dx.doi.org//0.1016/j.applanim.2006.05.042

Studnitz M, Jensen MB and Pedersen LJ 2007 Why do pigs root and in what will they root? A review on the exploratory behaviour of pigs in relation to environmental enrichment. Applied Animal Behaviour Science 107: 183-197. http://dx.doi.org/10.1016 /j.applanim.2006.11.013

Valros A, Ahlstrom S, Rintala $H$, Hakkinen $\mathbf{T}$ and Saloniemi H 2004 The prevalence of tail damage in slaughter pigs in Finland and associations to carcass condemnations. Acta Agriculturae Scandinavica Section A-Animal Science 54: 213-219. http://dx.doi.org//0.1080/090647005I0009234

Van De Weerd HA, Docking CM, Day JEL, Breuer K and Edwards SA 2006 Effects of species-relevant environmental enrichment on the behaviour and productivity of finishing pigs. Applied Animal Behaviour Science 99: 230-247. http://dx.doi.org /10.1016/j.applanim.2005.10.014

Wright AJ, Powney SL, Nevel A and Wathes CM 2009 Pig welfare assessment: development of a protocol and its use by veterinary undergraduates. Journal of Veterinary Medical Education 36: 50-6I. http://dx.doi.org// 0.3 I38/jvme.36.I.50 